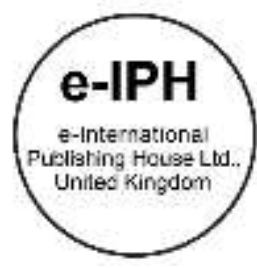

\title{
Characteristics of Tokiwadaira Neighbourhood Park in Matsudo, Japan: A space for the elderly
}

\author{
Prita Indah Pratiwi ${ }^{1}$, Katsunori Furuya ${ }^{1}$ \\ 1 Environmental Science and Landscape Architecture Course, Graduate School of Horticulture, \\ Chiba University, 648 Matsudo Matsudo-shi Chiba 271-8510 Japan \\ pritaindahpratiwi@ymail.com, k.furuya@faculty.chiba-u.jp \\ Tel: +6281382426570
}

\begin{abstract}
Tokiwadaira is one of the districts most populated by elderly in Japan. This study compared the preferences of danchi and apartment residents to examine the neighbourhood park preferences as well as neighbourhood park similarity. This research was conducted in three stages, including a spatial preference survey, analysis, and interpretation. A Welch's t-test and correspondence analysis were applied. Results demonstrated three significant differences between danchi and apartment residents, namely park preference, length of visit, and preferred park elements. There were four similarities among Tokiwadaira neighbourhood parks. These results may help urban planners optimise existing features of neighbourhood parks to encourage use.
\end{abstract}

Keywords: landscape preference; neighbourhood parks; resident participation

eISSN: 2398-4287 @ 2018. The Authors. Published for AMER ABRA cE-Bs by e-International Publishing House, Ltd., UK. This is an open access article under the CC BYNC-ND license (http://creativecommons.org/licenses/by-nc-nd/4.0/). Peer-review under responsibility of AMER (Association of Malaysian Environment-Behaviour Researchers), ABRA (Association of Behavioural Researchers on Asians) and cE-Bs (Centre for Environment-Behaviour Studies), Faculty of Architecture, Planning \& Surveying, Universiti Teknologi MARA, Malaysia.

https://doi.org/10.21834/e-bpj.v3i9.1513

\subsection{Introduction}

Creating an urban green space is a major task in realigning the urban structure of Japan. Japanese cities must prepare for the coming "grey society". Studies have already addressed this problem by examining green-space perceptions, preferences, and behaviours in Japan. Mutiara and Kinoshita (2011) described that low-level neighbourhood attachments are positively correlated with decreased park activity. Infrequent community involvement in park management is also a primary factor contributing to the decreased sense of community belonging. The challenge is thus to increase public trust by offering access to urban green spaces as well as participation in park planning and management.

In Japan, there is a strong focus on economic growth. However, there has been significant economic stagnation over the past generation. This has damaged both families and communities, resulting in a society problematized by increasing age and a declining birth rate. The Tokiwadaira district is located in the northeast of Tokyo, where the oldest semi-public housing was built during the early 1960s. Demographics there are changing very fast. In 2017 , the total population of Tokiwadaira was $28,875(14,231$ males and 14,644 females), including 14,932 households. Of this population, $38.29 \%$ (11,056 people) lived in the Tokiwadaira housing complex. In 2016 , $45.6 \%$ of all residents aged 65 years and older lived in Tokiwadaira danchi (housing complexes). In 2017, this rose to 47.5\%. Most elderly danchi residents moved into these buildings after retirement and now live alone. While private apartments surround the Tokiwadaira housing complex, most residents seem to ignore both the ageing buildings and elderly residents. The lonely-death phenomenon is also rarely discussed. The emergency of Kodokushi may also be explained as a result of an increase in single-person households such as elderly people (Tamaki, 2014) so that it is crucial to investigate their environmental activities and the tendency of preference in TNP as potential public space. This study began with the assumption that residents of different dwelling types may prefer

eISSN: 2398-4287 (C) 2018. The Authors. Published for AMER ABRA cE-Bs by e-International Publishing House, Ltd., UK. This is an open access article under the CC BYNC-ND license (http://creativecommons.org/licenses/by-nc-nd/4.0/). Peer-review under responsibility of AMER (Association of Malaysian Environment-Behaviour Researchers), ABRA (Association of Behavioural Researchers on Asians) and cE-Bs (Centre for Environment-Behaviour Studies), Faculty of Architecture, Planning \& Surveying, Universiti Teknologi MARA, Malaysia.

https://doi.org/10.21834/e-bpj.v3i9.1527 
different types of neighbourhood parks based on available activities, elements, and disturbances in the park. It was therefore considered necessary to investigate the preferential differences between danchi and apartment residents in addition to neighbourhood park similarity regarding the contained activities, elements, and disturbances in the park.

1.1 Purpose of the study

The purpose of this study was to investigate the neigbourhood park preference between two type of residents; what kind of activities, park elements, and disturbances in the park that they experienced. From the investigation, it is expected to formulate the characteristics of preferable green space for elderly people and implication of having suitable outdoor space surrounding old apartments.

1.2 Objective of the study

In line with the purpose, the objectives of the study were to identify the social characteristics of residents, to determine the significant difference in neighbourhood park preference, activities, park elements, and disturbances in the park between danchi and apartment residents, and to analyse the similarity among neighbourhood parks that is suitable for residents.

\subsection{Literature Review}

A neighbourhood is characterized by the significance of the physical change, physical boundaries and local landmarks in creating a sense of belonging and quality of life among the dwellers (Omar et al., 2016b). A neighbourhood environment can be divided into three major features; the physical, social and environment services. The physical environment is the structures and buildings. The social environment is the relationship among residents such as honesty, trust and cooperation. Meanwhile, service environment is the resources like institutions, transportation, recreational area and many others (Pearson, Bentham, Day and Kingham, 2014). Neighbourhood areas supply rich geographical, sociological, economic and psychological benefits (Cox et al., 2013). Furthermore, experiencing the environment has not only a psychological but also a physiological benefit. Alabbasi and Said (2018) described that environmental exposure means visiting urban parks and open spaces, could encouraging people to be physically active. It is essential that physical activity like walking, jogging, cycling or swimming be acknowledged as a necessary daily intervention to increase the quality of life of individuals with health problems including obesity, metabolic syndrome, diabetes and heart disease (Janicas, 2014). Furthermore, another typical physical activity, forest walking generated a significant decrease in physiological response, such as pulse rate and systolic and diastolic blood pressure. Besides that, it also can reduce psychological responses like tension, anger, fatigue, depression, confusion and anxiety as well as improve positive emotion (Yu et al., 2017). It is proven that outdoor physical activity causes a more positive mood and attitude than indoor activity (Sandifer et al., 2015).

The growing elderly population is a major concern, not only financially, but socially as well. Performing recreational activities for the elderly is a must for them to age successfully. Activities performed within a nearby park are one of the simplest forms of recreation. A successful park is categorized as one that satisfies the physical, psychological and social needs of the elderly people. The design of park must compensate for physical limitations that the elderly clients have and also meet those needs of the elderly as well. Identifying specific environmental concerns and their related design criteria will assist the designer in providing design solutions which will encourage the elderly to use the outdoor spaces (Othman and Fadzil, 2017).

\subsection{Methodology}

\section{1 Study Area}

One of the districts in Matsudo city, Tokiwadaira was comprised of a commercial area surrounded by residences, urban facilities, and green infrastructure. This study focused on residents' preference of neighbourhood parks. These parks were spread all throughout the Tokiwadaira District, including 1) Himawari Park, 2) Fuyou Park, 3) Aberia Park, 4) Shoubu Park, 5) Hanamizuki Park, 6) Kanegasaku Park, 7) Tsubaki Park, 8) Sakura Park, 9) Sarubia Park, 10) Kunugi Park, 11) Mucho Park, 12) Yamabuki Park, 13) Popura Park, 14) Shirakashi Park, 15) Wakaba Park, 16) Yanagimachi Children Playground, 17) Tokiwadaira Park, 18) Kanna Park, and 19) Kodemari Park.

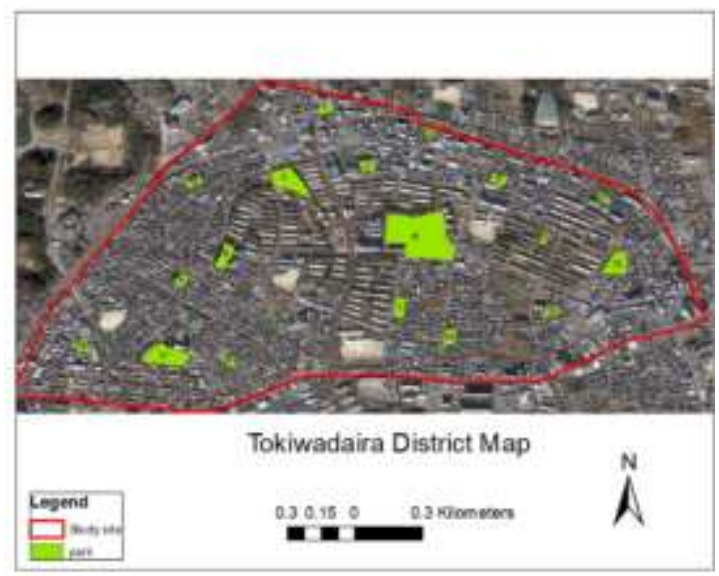

Fig. 1 Map of study area 


\subsection{Data collection}

This research obtained personal park preferences among local residents. All respondents were residents of Tokiwadaira within a $500 \mathrm{~m}$ boundary of each neighbourhood park. The boundary represents the approximate distance the average person can walk in roughly five minutes (a speed of $5.95 \mathrm{~km} / \mathrm{h}$ ) (Hamilton, 2017). Data were obtained through postal questionnaire surveys conducted among 2,020 residents. A combined 93 danchi and 127 apartment residents responded.

\subsection{Data Analysis Procedure}

Based on previous studies (Lucas, 1991; Pratiwi et al., 2014; Gunawan and Pratiwi, 2015), this study's design concept consisted of a spatial preference survey, preference analysis, and interpretation.

\subsubsection{Spatial preference survey}

The spatial preference survey was conducted to ascertain residents' attributes and identify residents' preference. Data were obtained through a postal questionnaire with an attached neighbourhood park map. Respondents were asked to draw a boundary around their most-preferred park. They were then asked about the number of parks visits each month, park activities, preferred park elements, and disturbances in the park. It was also necessary to clarify resident attributes, including gender, age, children, employment status, and length of stay. As Pratiwi et al. (2014) suggested, these factors may lead to differences in both perception and preference.

\subsubsection{Preference analysis}

Analysis of park preferences examined significant differences in preference based on dwelling type. There were 10 potential neighbourhood park activities and one answer indicating no activity. There were nine preferred park elements (See Figure 6). In addition, there were 11 disturbances in the park to choose from. A Welch's t-test was performed to examine the different responses.

Correspondence analysis of park preference. This analysis was used to compare similarities among neighbourhood parks based on activities, park visit time, preferred park elements, and disturbances in the park. The correspondence analysis was conducted as follows (see Kusuma et al., 2016): (1) a contingency table was arranged, (2) the proportion of inertia value in columns and rows based on the profile was calculated, (3) a singular value decomposition based on the row and column of inertia was calculated, and (4) the results were interpreted.

\subsection{Interpretation}

Analysis revealed significant differences among resident park preferences and a significant dependency between park preference and resident attributes. This could become a prominent point for discussion and a priority during future design consideration.

\subsection{Findings}

\subsection{Residents Social Characteristics}

Most danchi respondents $(\mathrm{N}=220)$ were male $(55 \%)$, while apartment residents were female $(57 \%)$. Regarding age, most danchi respondents $(57 \%)$ were older than 70 , while most apartment residents $(60 \%)$ were around $40-49$. About $85 \%(n=187)$ did not have children at home. Half of all respondents were employed $(50 \% ; n=110)$, while the other half was retired. Most $(27.3 \%)$ respondents had lived in the current area for 11-20 years, followed by 21-30 years (23.182\%) (Figure 2).

\subsection{Environmental Activities in the Tokiwadaira Neighbourhood}

Despite $84 \%$ of all respondents $(n=184)$ not having a volunteering activity, $61 \%$ of danchi residents expected to volunteer for both less than 1 hour per day and per month. Most apartment residents (51\%) expected to volunteer for $1-12$ hours per day, while they only expected to volunteer for 1-40 hours per month (44\%). Danchi residents tended to have higher expected volunteering activity. When asked about gardening, about $56 \%$ of danchi respondents indicated that they had gardened and continued to do so. A majority (57\%) of residential dwellings were surrounded by large quantities of green space. Meanwhile, green space activities significantly varied, ranging from $24 \%$ of danchi respondents and $30 \%$ of apartment residents who did not frequently engage to $31 \%$ and $13 \%$ who used them almost daily, respectively (Figure 3).

\subsection{TNP Preferences and Length of Park Visits}

There were significant differences in preference between danchi and apartment residents regarding neighbourhood parks in the Tokiwadaira district $(\mathrm{p}=0.000)$. The majority $(35.5 \%)$ of danchi residents only preferred one of selected six neighbourhood parks, while apartment residents preferred one of selected 12 neighbourhood parks (Figure 4). Danchi residents spent more time in neighbourhood parks than apartment residents $(p=0.052)$ (Figure 5).

\subsection{Activities, Preferred Park Elements, and Disturbances in Park}

There were no significant differences in preferred park activities and disturbance in the park between danchi and apartment residents. Meanwhile, a significant difference regarding preferred park elements between danchi and apartment residents was found $(p=0.000)$. Apartment residents had high preferences for a tree canopy to provide shade $(28.2 \%)$. This was followed by well-maintained green spaces $(11.4 \%)$, good quality paths $(5.9 \%)$, quiet places $(5.9 \%)$, a well-maintained children playground $(2.3 \%)$, good quality sports fields 
$(2.3 \%)$, and benches (1.8\%). Danchi residents had high preferences for benches (14.5\%), well-maintained green spaces (11.4\%), trees $(7.3 \%)$, good quality paths $(5 \%)$, good quality sports fields $(1.8 \%)$, well-maintained children playgrounds $(1.4 \%)$, and quiet places $(0.9 \%)$ (Figure 6).

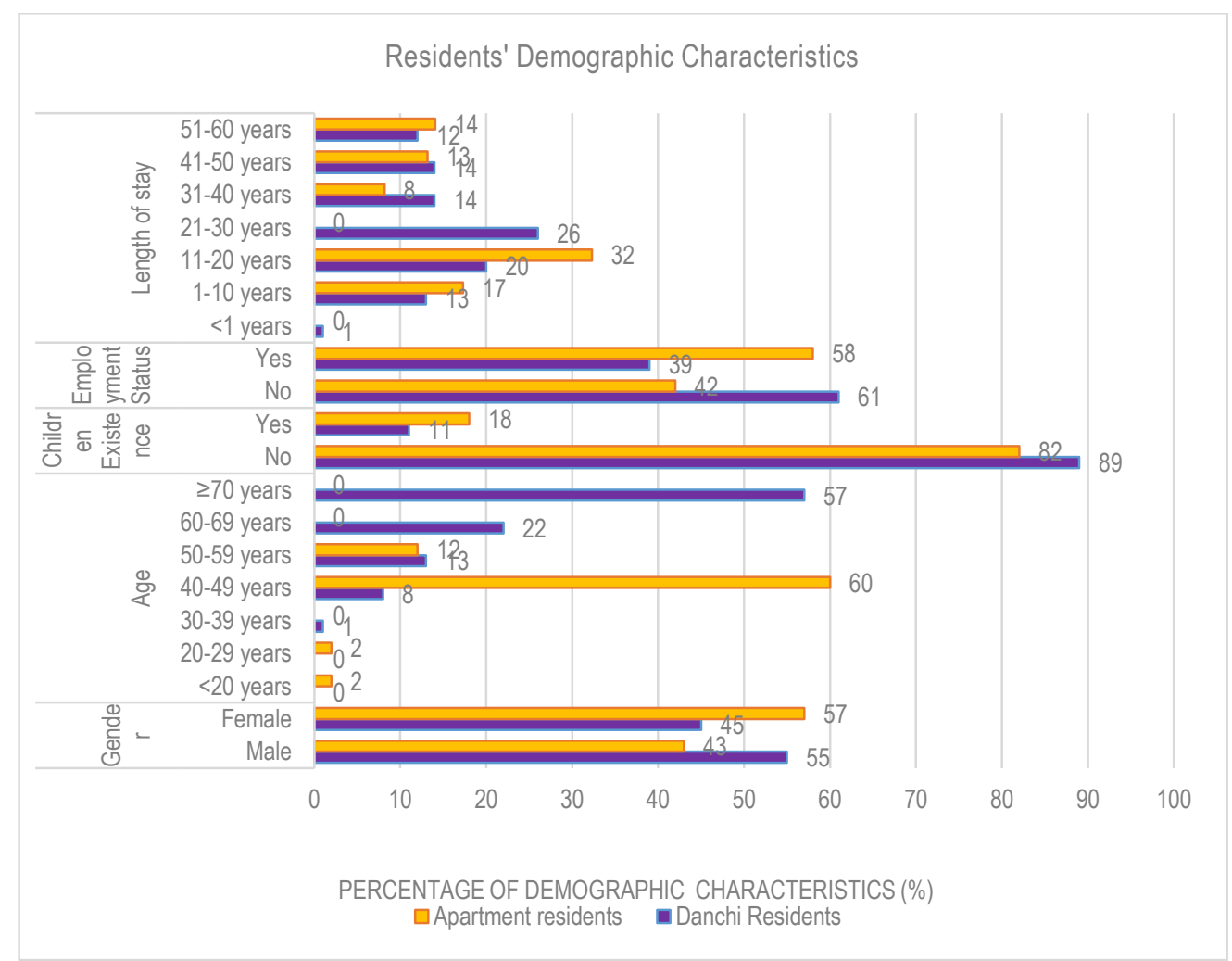

Fig. 2 TNP demographic characteristics

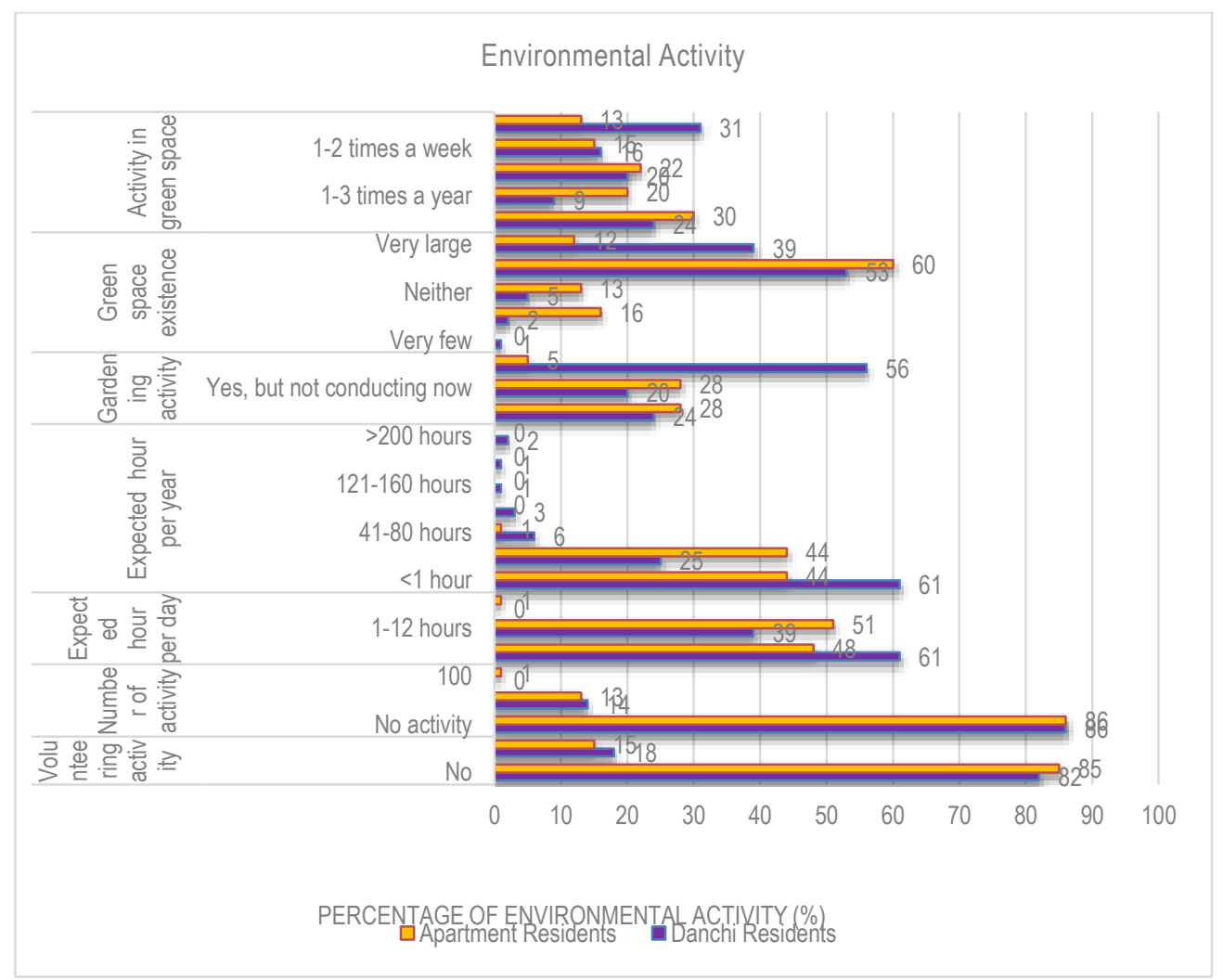

Fig. 3 Environmental activities 


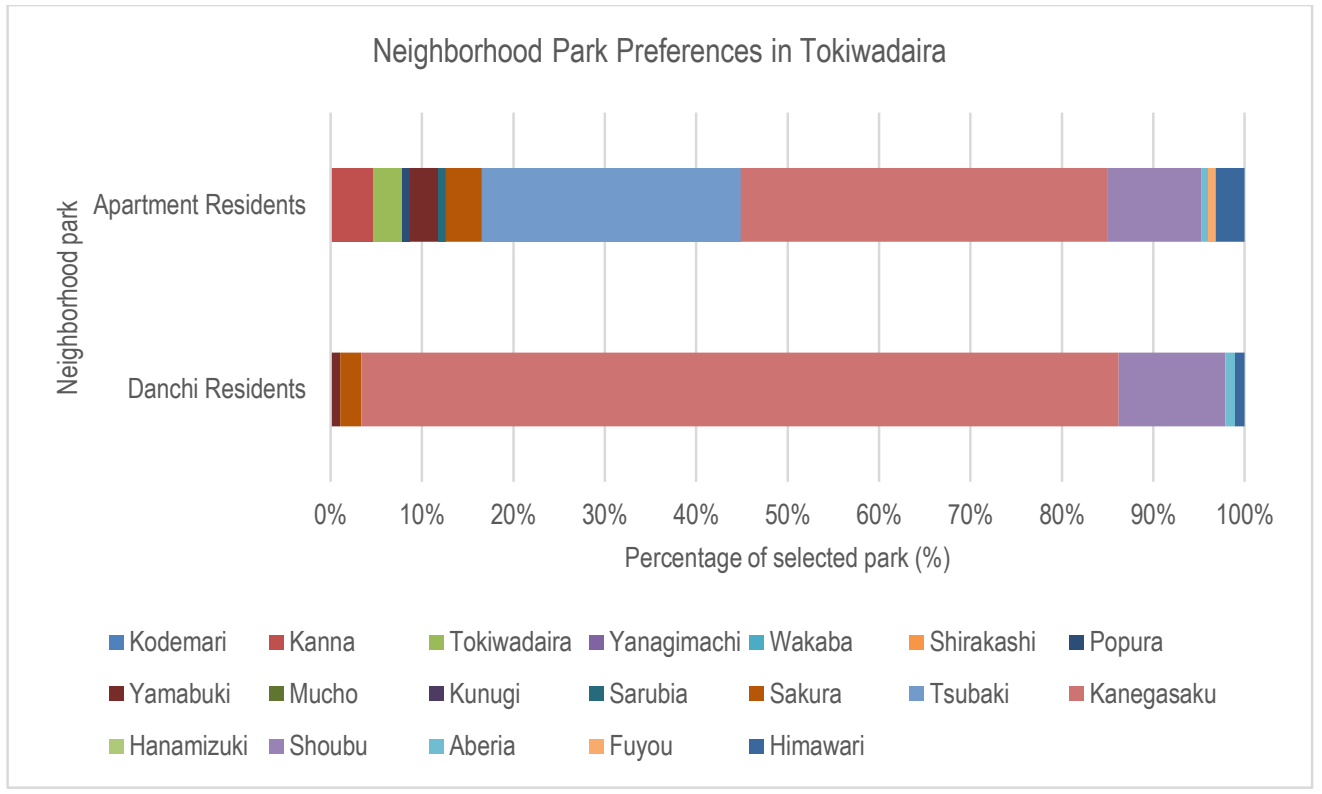

Fig. 4 Neighbourhood park preferences of danchi and apartment residents

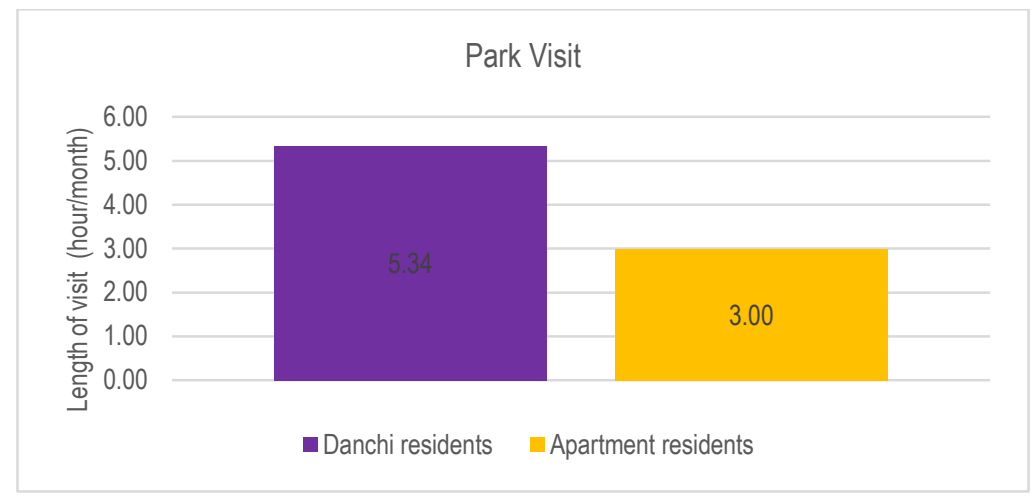

Fig. 5 Length of neighbourhood park visit

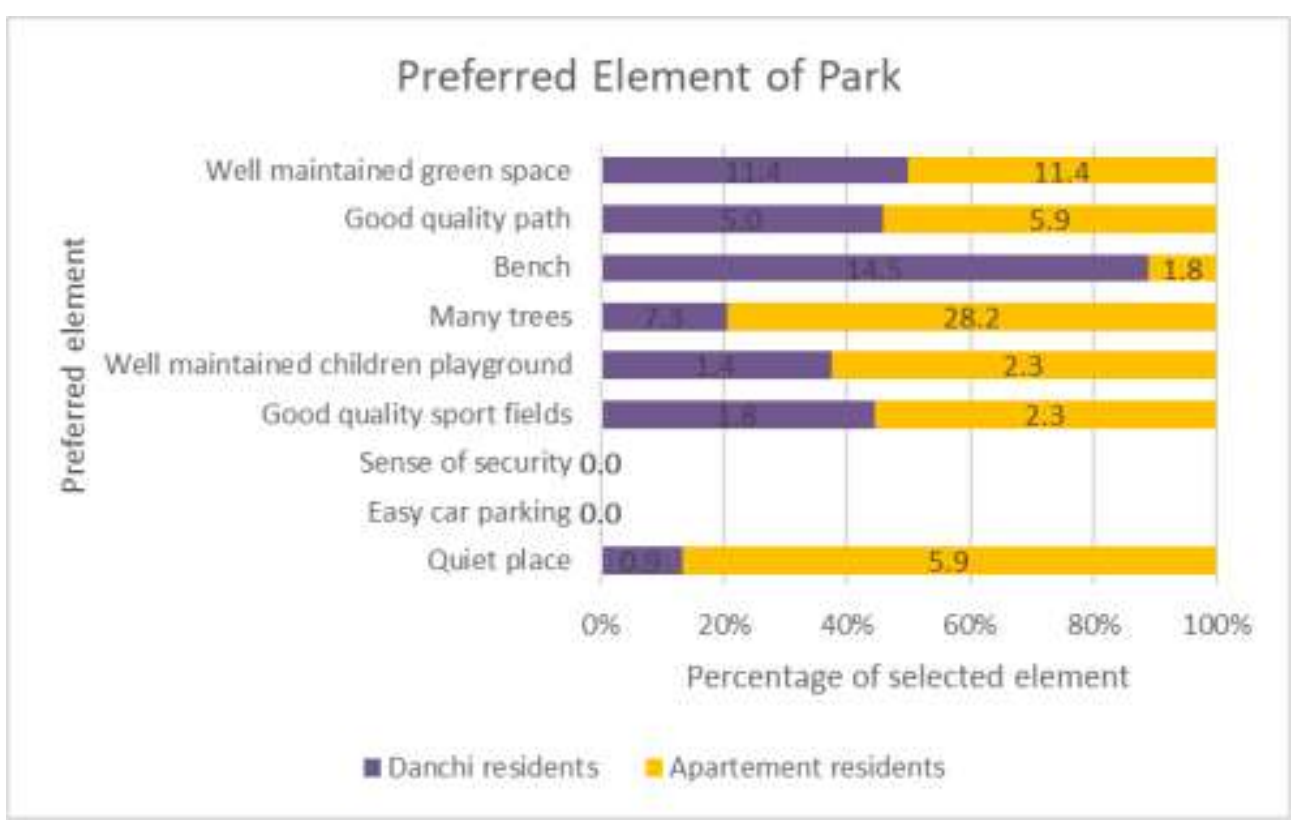

4.5 Correspondence Analysis of Neighbourhood Parks

Fig. 6 Preferred element of the neighbourhood park 
Based on a correspondence analysis, there was a significant difference in dependencies between preferred neighbourhood parks and green space existence near resident dwellings $(p=0.037)$. Figure 7 shows that most highly preferred neighbourhood park in the TNP was Kanegasaku. This park was similar to parks such as Shoubu and Tsubaki. Second, a significant dependency between activities at neighbourhood parks and age was found $(p=0.013)$. Figure 8 shows that the most highly preferred activity in TNP is enjoying nature. Enjoying nature was also similar to activities such as accompanying children, socialising with neighbours, and walking the dog. Residents aged 70-79 years often performed these activities. Third, a significant dependency was detected between neighbourhood park activities and preferred park elements $(p=0.000)$. Figure 9 shows that the most highly preferred park element in TNP is tree canopy. The number of trees was also similar to other park elements such as quiet places. Activities such as walking the dog and spending time with family were performed under tree shade. On the other hand, enjoying nature tended to take place in good quality sports fields. Forth, a significant difference was found in dependencies between disturbance in parks and preferred park elements $(p=0.000)$. Figure 10 shows that the most frequently reported disturbance in TNP was inadequate benches. Difficult car parking was also highly reported.

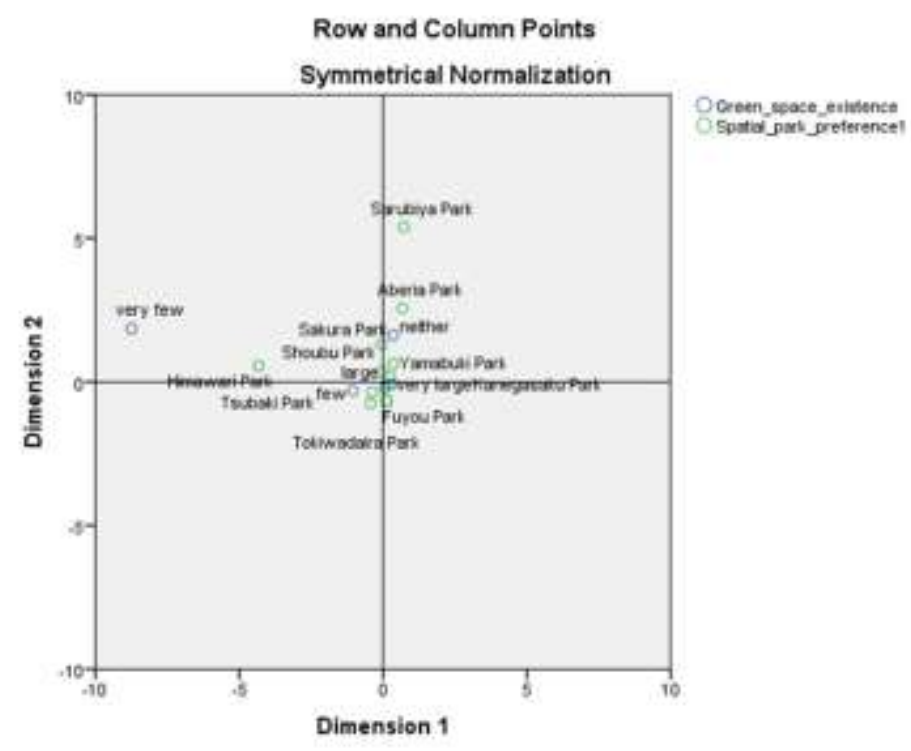

Fig. 7 Proximity of neighbourhood park and the existence of green space

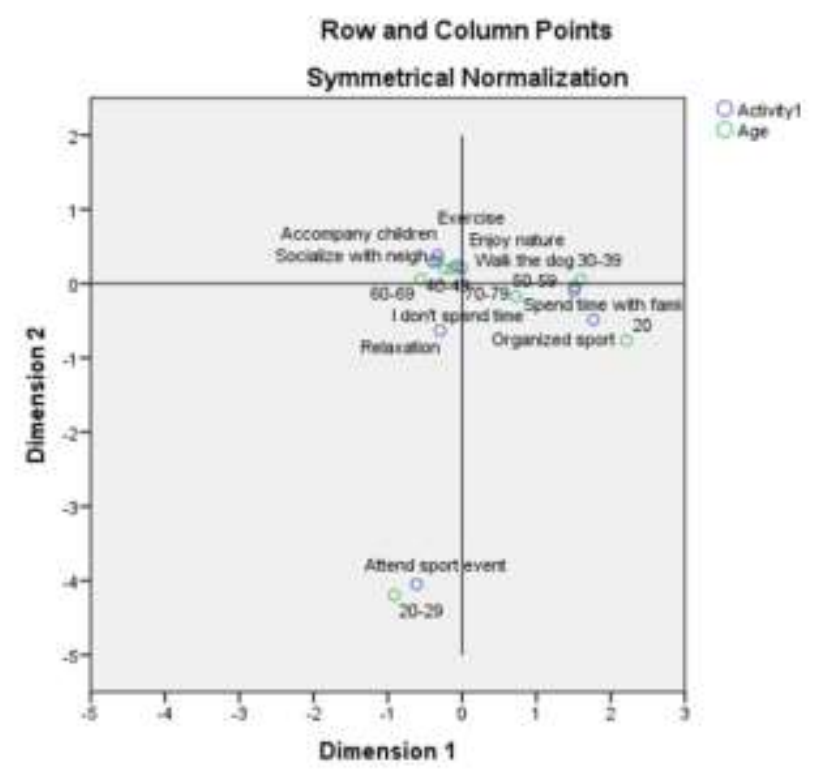

Fig. 8 The proximity of park activity and age 


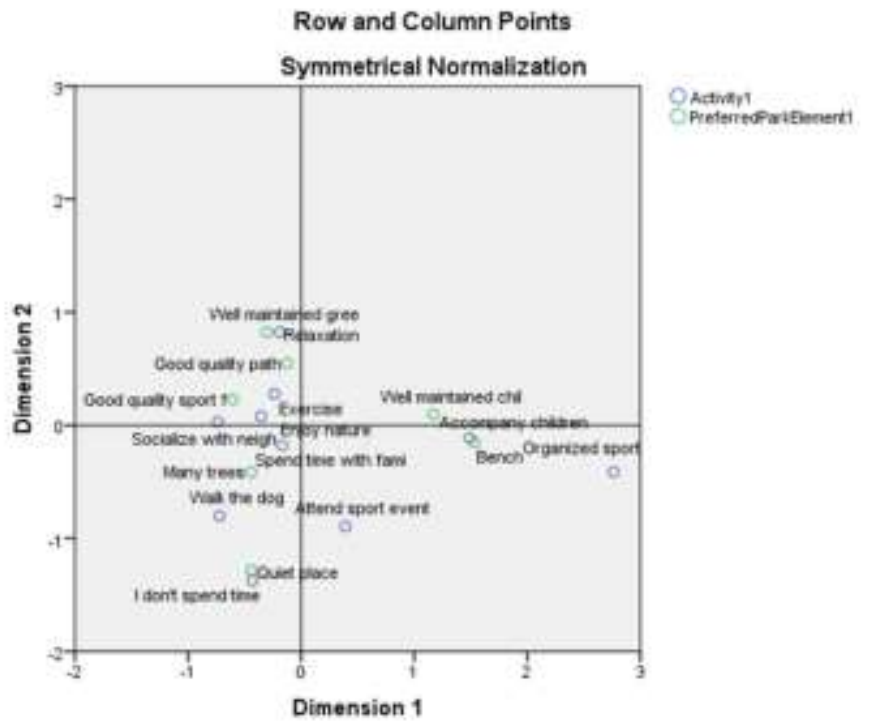

Fig. 9 Proximity of preferred park elements and park activity

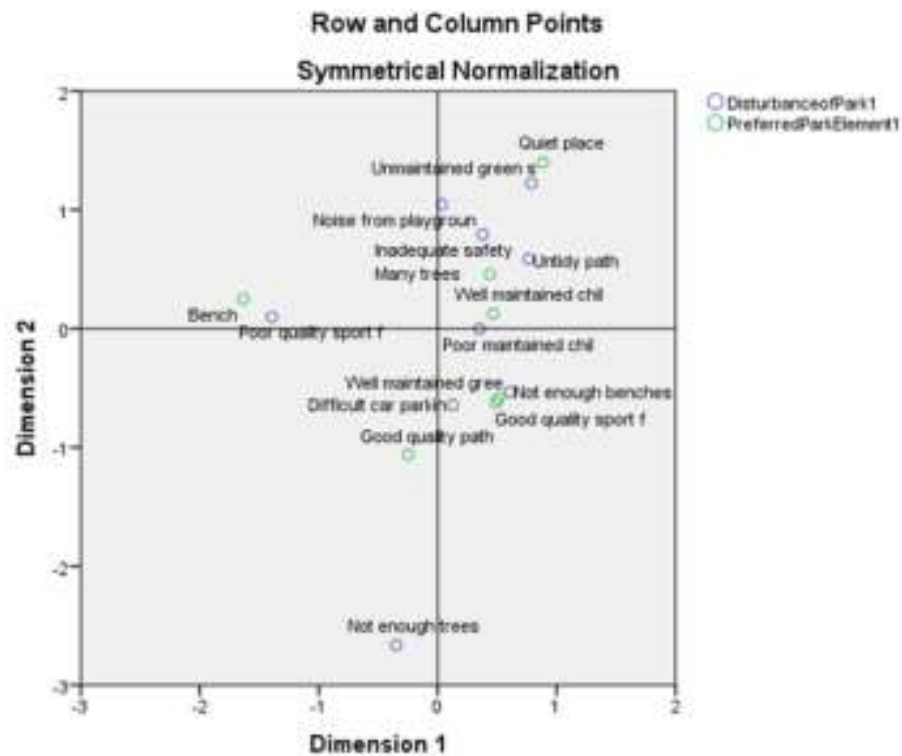

Fig. 10 Proximity of preferred park elements and disturbance in the park

\subsection{Discussion}

\subsection{Neighbourhood Characteristics}

The Tokiwadaira district contains two types of neighbourhoods (i.e., danchi and apartments). Danchi are mostly occupied by residents aged 70 and above; these residents are typically retired and have lived in the neighbourhood from 21-30 years. On the other hand, apartments are typically occupied by residents aged 40-49 years; these residents are usually employed and have lived in the neighbourhood from 11-20 years. Based on environmental activity, neighbourhood characteristics indicate that danchi residents tend to garden at home due to large green spaces surrounding the danchi complex. As explained by Pratiwi et al. (2018), female residents exhibit more environmental behaviour and have more social ties than male residents. They also tend to grow plants and have a high social attachment to the neighbourhood. Although apartment residents had gardening experience and large green spaces, they did not typically work in gardens. Employed residents spent a significant amount of time in offices; this may affect their environmental behaviour (Pratiwi et al., 2018; Laurens, 2012).

\subsection{Significant Differences in Neighbourhood Park Preferences}

Danchi and apartment residents had different park preferences. Danchi residents preferred Kanegasaku Park, while apartment residents preferred Kanegasaku Park, Tsubaki Park, and Shoubu Park. Danchi residents over 70 years of age preferred to visit large parks within short walking distances. Neighbourhood parks located close to home will be visited more frequently than those located 
further than 15 minutes' walking distance (Willemse, 2015). Further, apartment residents preferred to visit a range of park sizes at variable distances from their dwellings. Large green spaces and variety of features encouraged residents to visit Kanegasaku Park and stay longer at this park than at the other parks (Veitch et al., 2012). On the other hand, litter, vandalism, and unclean toilets may deter park use. Danchi and apartment residents also had different park element preferences. Danchi residents preferred benches, while apartment residents preferred trees. Bench availability was crucial for danchi residents who stayed for extended periods; these provided rest before moving onto other activities.

\subsection{Neighbourhood Park Similarity}

Green space similarity among parks was investigated through a tendency analysis and perceptual mapping. Kanegasaku Park had similar characteristics to both Shoubu Park and Yamabuki Park. The three most-preferred parks were selected due to similar large green spaces surrounding dwelling area. These parks may attract visitors aged 70-79 years due to several shared characteristics and available activities, such as the ability to enjoy nature, walk the dog, exercise, accompany children, socialise with neighbours, and relax. Crucial park elements are needed to perform these activities, including tree canopies and well-maintained green spaces; these elements should be considered first in neighbourhood park design. It is also important to address disturbance in parks such as not enough benches and difficult car parking.

\subsection{Limitation of Study}

The following are the limitations associated with the study: First, the study location was focused on the preference of neighbourhood parks; other public spaces were not selected. Second, this was not real-time measuring preference which might limit potential activity, preferred element, and disturbance in the park, but using postal questionnaire. Third, the role of psychological response which may be the important parameter of the need of green space was not explored.

\subsection{Conclusion and Recommendations}

Results indicated three significant differences between danchi and apartment residents (i.e., neighbourhood park preference, length of visit, and preferred park element. There were four similarities among the examined neighbourhood parks (i.e., green space existence, age-based activities, park-element based activities, and disturbance in parks). This information may help urban planners conduct participatory planning with the community and optimise local features through consideration of park strengths and weaknesses to encourage use by the elderly. It is especially important to improve tree management. This can be accomplished by conducting a treehealth survey and managing the tree database to conserve existing prioritised local landscape elements. Green spaces should also be maintained, including sports fields and lawns, while other park features should be improved, such as bench availability and car parking for non-local visitors.

Further research engaged at the psychological and physiological effect of experiencing nature walking through the tree canopy at a park. Furthermore, there must be a detailed mood and anxiety inventory and proper physiological parameters, whether this type activity is necessary for increasing quality of life.

\section{Acknowledgements}

We would like to thank Takayoshi Enomoto who supports the literature source for this study. We also would like to thank the danchi and apartment residents in Tokiwadaira, Matsudo city, Japan who had participated in this study as respondents.

\section{References}

Alabbasi, A. M., \& Said, I. (2018). Restorative effects of open spaces on the physiological health of obese adults in Saudi Arabia. Environment-Behaviour Proceeding Journal, 3(8), 55-64.

Cox, E., Turley, A., Davies, B., \& Harrison, M. (2013). The condition of Britain. Love thy neighbourhood : People and place in social reform. IPPR North. Retrieved from http://www.ippr.org/assets/media/images/media/files/publication/2013/11/love-thy-neighbourhood_Nov2013_11478.pdf. Retrieved: August 2018.

Gunawan, A., \& Pratiwi, P. (2015). User behaviour on specific environment in bogor botanical garden. ASEAN Journal on Hospitality and Tourism, 14(1),3-12.

Hamilton, K., Kaczynski, A.T., Fair, M. L., \& Levesque, L. (2017). Examining the relationship between park neighborhoods, features, cleanliness, and condition with observed weekday park usage and physical activity: a case study. Journal of Environmental and Public Health, 2017, 1-11.

Janicas K. 2014. Exercise as a treatment in intellectual and developmental disability. Journal on Developmental Disabilities, 20(1), 122-127.

Kusuma, A. W. A., Srinadi, I. G. A. M., \& Sari, K. (2016). Aplikasi analisis korespondensi untuk melihat karakteristik usaha pariwisata di provinsi bali. E- Jurnal Matematika, 5(2), 76- 81

Laurens, J. M. (2012). Changing behavior and environment in a community-based program of the riverside community. Procedia-Social and Behavioral Sciences, 36 , 372-382. 
Lucas, O. W. R. (1991). The Design of Forest Landscape. New York: Oxford University Press.

Mutiara, S., \& Kinoshita, I. (2011). Characteristics of public small park usage in Asia pacific countries: case study in Jakarta and Yokohama city. Procedia-Social and Behavioral Sciences, 35(2012), 412-419.

Omar, K. A., Omar, D., Othman, S., \& Yusoff, Z. M., et al. (2016). Reviewing youth facility requirements for low-cost housing in Malaysia. Procedia - Social and Behavioral Sciences, 222, 702-709.

Othman, A. R., \& Fadzil, F. (2015). Influence of outdoor space to the elderly wellbeing in a typical care centre. Procedia - Social and Behavioral Sciences, 170(2015), 320 -329 .

Pearson, A. L., Bentham, G., Day, P., \& Kingham, S. (2014). Associations Between neighbourhood characteristics and obesity and related behaviours among adult New Zealanders. BMC Public Health, 2014, 14(553).

Pratiwi, P. I., Sulistyantara, B., Gunawan, A., \& Furuya, K. (2014). A comparative study on the perception of forest landscape using LIST method between university students of Japan and Indonesia. Jurnal Managemen Hutan Tropika, 20(3), 167-178.

Pratiwi, P. I., Kim, M., \& Furuya, K. (2018). Difference in perception of urban green spaces between danchi and apartment residents in Tokiwadaira, Matsudo city, Japan Manuscript submitted for publication.

Sandifer, P. A., Sutton-Grier., A. E., \& Ward, B. P. (2015). Exploring connections among nature, biodiversity, ecosystem services, and human health and well-being: opportunities to enhance health and biodiversity conservation. Ecosystem Services, 12(2015), 1-15.

Tamaki, T. (2014). Live and die in solitude away from the family: issues relating to unattended death kodokushi in Japan. Housei Riron, 46 (4), $203-218$.

Turan, S. O., Pulatkan, M., Beyazli, D., \& Özen, B.S. (2015). User evaluation of the urban park design implementation with participatory approach process. Procedia Social and Behavioral Sciences. 216(2016): 306-315.

Veitch, J., Ball, K., Crawford, D., Abbott, G. R., Psych, G. D., \& Salmon, J. (2012). Park improvements and park activity: a natural experiment. American Journal of Preventive Medicine, 42(6), 616-619.

Willemse, L. (2015). Some perceptions and preferences of residents' use of community neighbourhood parks in Mitchells Plain, Cape Town. Town and Regional Planning, 2015(66), 15-30.

Yu, C., Lin, C., Tsai, M., Tsai, Y., \& Chen C. (2017). Effects of short forest bathing program on autonomic nervous system activity and mood states in middle-aged and elderly individuals. Int. J. Environ. Res. Public Health, 14(8), 1-12.

ciences, $170,642-652$. 